\title{
INTEGRATION OF TERRESTRIAL AND UAV PHOTOGRAMMETRY FOR THE ASSESSMENT OF COLLAPSE RISK IN ALPINE GLACIERS
}

\author{
M. Scaioni a,b, L. Barazzetti ${ }^{\text {a,b,1 }}$, M. Corti ${ }^{\text {b }}$, J. Crippa ${ }^{\text {b }}$, R.S. Azzoni ${ }^{\text {c, D. Fugazza }}{ }^{\text {d }}$, M. Cernuschi ${ }^{\text {e }}$, G.A Diolaiuti c \\ ${ }^{a}$ Dept. of Architecture, Built Environment and Construction Engineering (DABC), Politecnico di Milano \\ via Ponzio 31, 20133 Milano, Italy - email: \{marco.scaioni, luigi.barazzetti\}@polimi.it \\ ${ }^{\mathrm{b}}$ Polo Territoriale di Lecco, Politecnico di Milano \\ via G. Previati 1/c, 23900 Lecco, Italy - email: \{manuel.corti, julien.crippa\}@mail.polimi.it \\ ${ }^{\mathrm{C}}$ Dept. of Environmental Science and Policy (DESP), Università degli studi di Milano \\ via Mangiagalli 34, 20133 Milano, Italy - email: \{guglielmina.diolaiuti, robertosergio.azzoni\}@unimi.it \\ d Dept. of Earth Sciences 'A.Desio', Università degli studi di Milano, \\ via Mangiagalli 34, 20133 Milano, Italy - email: davide.fugazza@unimi.it \\ e Agricola 2000 S.C.P.A., 20067 Tribiano (MI), Italy - email: massimo.cernuschi@gmail.com
}

KEY WORDS: Forni Glacier, Glaciology, Photogrammetry, Structure-from-Motion, UAV/UAS

\begin{abstract}
:
The application of Structure-from-Motion photogrammetry with ground-based and UAV-based camera stations can be effectively exploited for modeling the topographic surface of Alpine glaciers. Multi-temporal repeated surveys may lead to geometric models that may be applied to analyze the glacier retreat under global warming conditions. Here the case study of Forni Glacier in the Italian Alps is presented. Thanks to the integration of point clouds obtained from the independent photogrammetric processing of ground-based and UAV blocks of images (captured on 2016), a complete 3D reconstruction also including vertical and sub-vertical surfaces has been achieved. This 3D model, compared to a second model obtained from a ground-based photogrammetric survey on September 2017, has been exploited to understand the precursory signal of a big collapse that might have involved tourists and hikers visiting the glacier ice tongue during summer. In addition to some technical aspects related to the acquisition and processing of photogrammetric data of glaciers, this paper highlights how Structure-from-Motion photogrammetry may help evaluate the risk of collapse in Alpine glaciers.
\end{abstract}

\section{INTRODUCTION}

\subsection{The risk related to mountain glaciers}

Under the current global warming conditions, the cryosphere is generally suffering from diffuse melting and localized collapsing phenomena (Kerr, 2012). Although this process has resulted in big disrupting events in Arctic and Antarctic regions (e.g., the Larsen B disintegration in 2002 - see Scambos et al., 2003), continental glaciers - and especially Alpine glaciers are the areas that have shown the most evident effects. By comparing the extension of the most continental glaciers during the last one hundred years, the retreat is generally impressive and almost continuous within time. On one side, the effect of the increased average air temperature generated a growth of ice melting speed. This resulted in a progressive loss of ice mass, in thickening of ice tongues, and shortening the longitudinal extension of glaciers. On the other hand, especially the terminal areas of Alpine glaciers underwent some local disruption processes, which caused a quicker melting process of the ice mass and an acceleration of the retreat.

The relevance of such local collapses is not only related to the global glacier retreat, which however may have a tremendous impact at regional level. The retreat or complete loss of a glacier, indeed, may have serious follow-ups on the ecology and the ecosystem of the downstream valley, but also it may influence the economy of a region. Local collapsing processes may have a quick evolution, resulting in risk for people, properties and infrastructures, as well as for the environment itself. In addition, the melting of glaciers or permafrost areas may result in weakening the soil stability, with consequent landslide or rockfall risk, as reported in Fey et al. (2017). The risk is higher when the glacier area is frequented by tourists and mountain hikers.

A typical case where such a kind of process is undergoing is offered by Forni Glacier, which is located in the alps within the National Stelvio Park (Northern Italy). A brief presentation of the study area can be found in Subsection 2.1. In the latest years, here the melting process has resulted in the formation of some circular deep crevasses on the surface of the terminal ice tongue. Due to the contemporary erosion of subglacial water, large areas have collapsed resulting in the formation of huge craters in the ice tongue, see Figure 1 . The event occurred during September 2017 (Fig. 1b) partially interrupted the active ice flow on the right hydrographic flank of the terminus, speeding up the melting process of this portion of the glacier.

${ }^{1}$ Corresponding author 


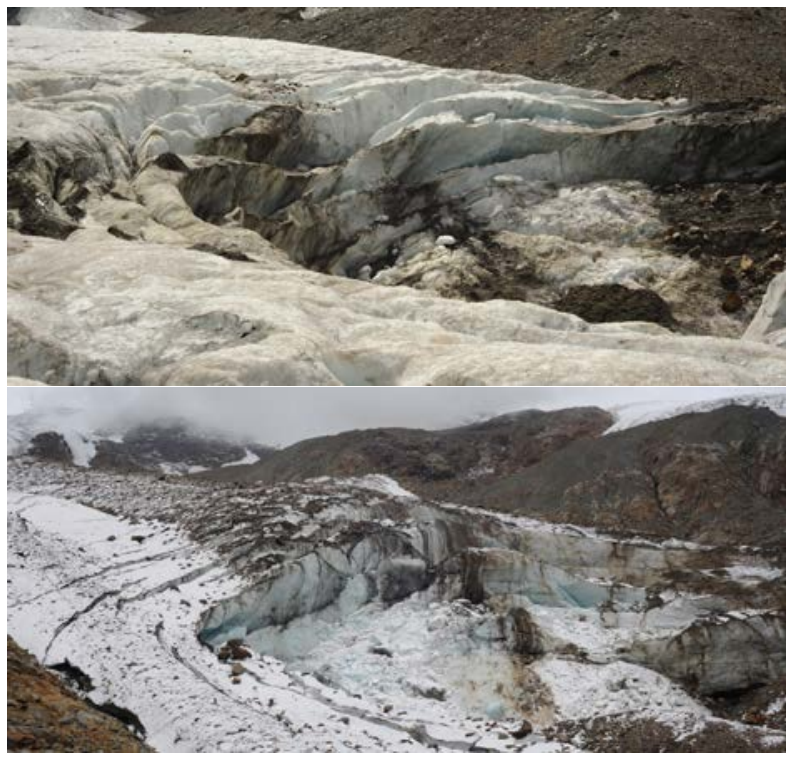

Figure 1. - Two examples of local collapses in the terminus area of Forni Glacier occurred in 2016 (at the top - 'a') and 2017 (at the bottom - 'b').

As mentioned above, the problem is tremendously severe under both glaciological and environmental perspectives. Indeed, this kind of events demonstrate that the melting process is not linear and might show sudden accelerations under global warming forcing. On the other side, the collapse illustrated in Figure 1b probably happened during night in a period where nobody was the glacier surface. Only a few weeks before, during August the terminus of Forni Glacier was crowded by several tourists and hikers, thanks to the easy access from a mountain hut in the nearby. This paper does not want to demonstrate how the precursory signals of this type of processes may be analyzed and used to predict forthcoming collapses. This process would require the integration of digital surface models (DSMs) of the glacier, ice-penetrating observation to measure the ice thickness, rheological and weather records, as well as measurement of subglacial water flow. On the other model, some typical surface patterns (e.g., circular crevasses) that are likely to be precursory signals of a collapse cab be observed and analyzed in 3D models obtain using photogrammetric techniques.

\subsection{Modelling the glacier surface using photogrammetry}

With the integration of Computer Vision and the Photogrammetry, fully automatic methods for image orientation (Barazzetti et el., 2011) and dense surface reconstruction (Eltner et al., 2016) have been developed. These new solutions have established what is commonly referred to with the term 'Structure-from-Motion' (SfM) photogrammetry (Westoby et al., 2012). Using a consumer-grade camera equipped with an adequate focal lens and using a suitable network geometry for the image acquisition, 3D models of topographic surfaces can be obtained without the need of using expensive and cumbersome long-range terrestrial laser scanners (TLS). A total station or GNSS sensors are needed for the measurement of a few ground control points (GCP) for georeferencing the resulting point cloud into a given reference frame.

The advantage of using SfM techniques rather than TLS is more evident in small projects or in areas which are difficult to be accessed. Indeed, thanks to the light weight of camera sensors, they can be also installed on the payload of unmanned aerial vehicles (UAV), see Colomina \& Molina (2014), Carboneau \& Dietrich (2016) and O’Connor et al. (2017). This opens the possibility to survey large areas with a nadir view or to reach areas that may not be accessible from the ground. In fact, while satellite remote sensing is expected to provide the major contribution for monitoring and investigating long timescale changes at medium/low spatial resolution, in many projects a higher level of detail is necessary. Whilst the use of sensors on manned aircrafts may fulfill these requirements, the costs involved and possible operational criticalities (e.g., due to safety concerns, flight regulations, distance from the aircraft base) may prevent their application. On the other hand, UAVs represent an interesting compromise between the required accuracy/resolution and budgetary problems. In some cases, the acquisition of a ground-based photogrammetric network may be also required, for example for 3D reconstruction of vertical and sub-vertical surfaces. Given a suitable geodetic reference, multi-platforms surveys may be integrated to obtain full 3D models which completely depict geomorphic objects under different point of views. A review on the application of photogrammetry to the study of Alpine glaciers can be found in Fugazza et al. (2017) and Scaioni et al. (2017).

This paper would like to describe the acquisition and processing steps of two data sets aimed at mapping risk on the surface of Forni Glacier. Photogrammetric data collected from ground-based stations (2016 and 2017) and UAV (2016) have been used to this purpose. While in Subsections 2.1 and 2.2 the case study and the adopted data sets are described, respectively, in Subsection 2.3 some aspects of photogrammetric data and point cloud processing are illustrated and then discussed in Subsection 2.4. Eventually, in Section 3 the plan for future investigations is drawn.

\section{EVALUATION THE COLLAPSE RISK OF FORNI GLACIER}

\subsection{Forni Glacier}

Forni Glacier (Ortles Cevedale mountain group) in the National Stelvio Park (Northern Italy) is one of the major storage of ice in the Italian Alps, which is currently suffering from a quick ablation process. The latest Italian Glacier Inventory (Smiraglia et al., 2015) reported the total glacier area as $11.34 \mathrm{~km}^{2}$, an altitudinal range between 2501 and 3673 m a.s.l., and a NorthNorth-Westerly aspect. Since this inventory was based on 2007 data, the successive separation of the multiple ice tongues, the loss of ice bulk at global level and the retreat resulted in a reduction of the reported extension. These are progressive processes that have been active in the latest decades but recently they have been showing a quick acceleration. Just to give an idea of the magnitude of the retreat process, during the Little Ice Age, which approximately extended from 1500-1850 
B.C., Forni Glacier spanned over an area of $17.80 \mathrm{~km}^{2}$ (Diolaiuti \& Smiraglia, 2010). On the other sides, some sectors of the lower part of glacier's main tongue are undergoing a local disruption process entailing first the formation of circular crevasses, to be followed by their collapse and the formation of large exposures of bedrock, see Figure 1. Other similar processes are documented in Azzoni et al. (2017). Such local processes are quite fast to develop: from their preliminary events to the full ice collapse the process may take less than one year to be completed. Monitoring the ice degradation process from a quantitative and qualitative point-of-view is of great importance for understanding the related dynamics and to apply rigorous numerical models. While the analysis of archive maps, medium resolution satellite images and digital elevation models (DEM) may provide an overview of the long-term processes, the application of close-range sensing techniques (see Rutzinger et al., 2016) from ground-based and UAV stations offers the unprecedented opportunity to operate a 4D reconstruction of the glacier geometry at both global and local levels. Recent research on this glacier can be found in Fugazza et al. $(2015 ; 2016 ; 2017)$.

\subsection{Available data sets}

Since 2007, several high-resolution DSMs have been derived to witness the dynamic evolution of the terminus tongue of Forni Glacier. While a more detailed description can be found in Scaioni et al. (2017), here we limit to give a short mention.

A DEM was produced using aerial photogrammetry based on a digital push-broom camera Leica ADS40 on 2007. This data set covers the full glacier and periglacial area with an average ground sample distance (GSD) of $65 \mathrm{~cm}$ and a cell resolution of $2 \mathrm{~m} \times 2 \mathrm{~m}$.

Two UAV flights covering the glacier terminus were operated in 2014 and 2016. The first survey covered both the terminus of the central and eastern ablation tongue of the glacier (Fugazza et al., 2015). It was flown on $28^{\text {th }}$ August 2014 using a SenseFly SwingletCam fixed wing aircraft. A Canon Ixus $127 \mathrm{HS}$ compact camera (16 Mpix sensor size, $4.3 \mathrm{~mm}$ focal length) was implemented in the payload. This drone was flown at a relative flying height of approximately $380 \mathrm{~m}$ above the average glacier surface, which resulted in an average GSD of $12 \mathrm{~cm}$. No GCPs were deployed during this flight, but the only information available for absolute georeferencing were the 291 camera-pose locations obtained from the onboard navigation-grade GNSS sensor (uncertainty in the order of \pm 2 $\mathrm{m})$.

The second flight was operated across two days (30 $30^{\text {th }}$ August and $1^{\text {st }}$ September 2016), see Fugazza et al. (2017). The drone employed in this mission was a customized quadcopter incorporating a Tarot frame 650 size, VR Brain 5.2 Autopilot \& APM Arducopter 3.2.1 Firmware. A Canon Powershot ELPH 320 HS compact camera (16 Mpix sensor size, $4.3 \mathrm{~mm}$ focal length) was implemented in the payload. A low relative altitude of $50 \mathrm{~m}$ with respect to the topographic surface was selected, which ensured an average GSD $=5.7 \mathrm{~cm}$. Eight GCPs were deployed on the glacier terminus and in the periglacial area in front of it (see Fig. 2). Such GCPs, made up of white and red targets (size $80 \mathrm{~cm}$ x $80 \mathrm{~cm}$ ) recognizable in the images, where measured by using a RTK-GNSS sensor.

During the acquisition time of 2016 UAV flight, a block made up of 134 images captured using an SLR (single lens reflex) camera Nikon D700 (CMOS sensor with 4256x2823 pix and a 50 -mm lens) from ground-based stations was operated This block covered the glacier terminus including the rock flanks, a part of the periglacial area, and the ending part of the central moraine over the main glacier tongue. In Figure 2a, a view of camera poses is displayed. The criterion applied for establishing the camera stations was to explore as many positions as possible from which the targeted region could be observed from multiple, redundant viewpoints. In particular, to optimize the SfM process, an attempt to find a trade-off between long baselines with convergent images (providing a better geometric intersection of corresponding rays) and shortbaselines with parallel images (helping the image-matching process adopted for image orientation and surface reconstruction), see Wenzel et al. (2013). Seven natural features were selected as GCPs on the glacier front for geo-referencing of terrestrial block. Their coordinates in the mapping reference frame were measured using a theodolite equipped with a reflector-less rangefinder. The position and heading of the theodolite station in the geodetic reference frame was found using RTK-GNSS. During September 2017, a new photogrammetric survey from ground-based stations was repeated after the impressive collapse shown in Figure 1b. This survey was using the same camera adopted in 2016 and following the same criterion for data acquisition (see Fig. 2b). Due to some technical problems, no measurements for absolute georeferencing could be obtained on 2017.

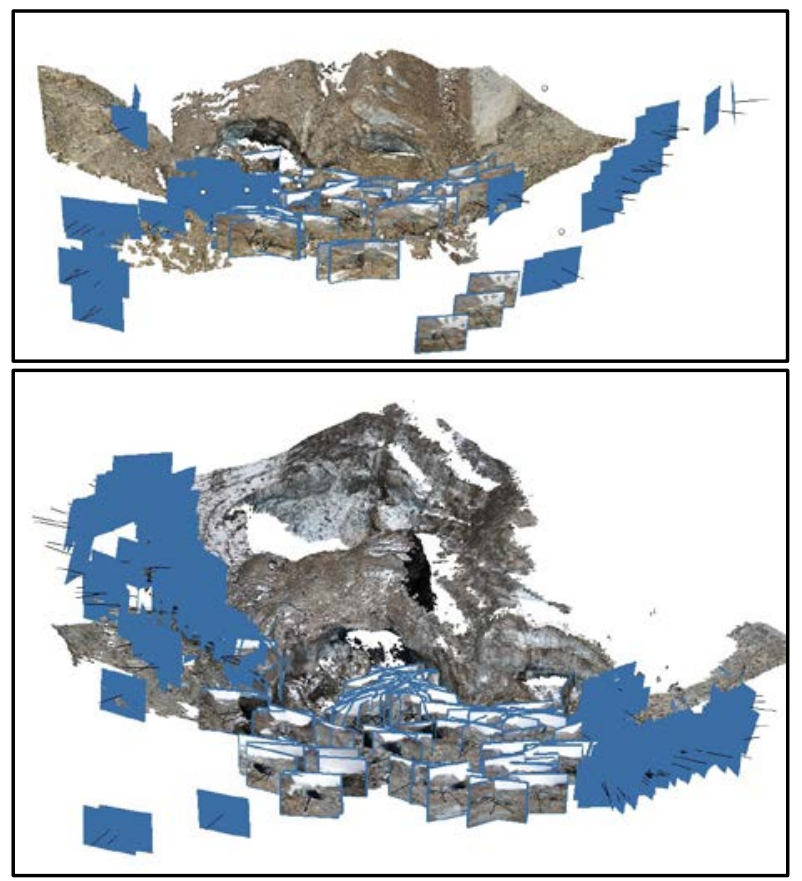

Figure 2. - Camera stations (blue rectangles) of terrestrial photogrammetric networks accomplished in 2016 (at the top - 'a') and 2017 (at the bottom - 'b'). 


\subsection{Photogrammetric reconstruction}

All photogrammetric blocks (2016 and 2017) were processed using a similar pipeline based on SfM photogrammetry. While more technical details on the standard workflow and on quality assessment issues may be found in Scaioni et al. (2017), here we would like to highlight some specific problems as well to show some new results coming from the survey carried out on September 2017.

2.3.1 Basic processing pipeline. All photogrammetric blocks have been processed by following as standard pipeline using Agisoft Photoscan ${ }^{\circledR}$ Professional (APP - www.agisoft.com). First tie points (TPs) have been extracted and matched using feature-based matching (see Hartmann et al., 2016). By using a Structure-from-Motion ${ }^{2}$ integrated to a bundle-block adjustment (BBA), the exterior orientation (EO) of the images, the ground coordinates of TPs, and the camera calibration parameters have been estimated. Some GCPs have been used for georeferencing in the mapping datum. Eventually, a dense matching technique has been adopted for deriving the point cloud describing the surface of the region of interest. In the case of dense matching, also another software package (Bentley ContextCapture $^{\circledR}$ - BCC) developed to cope more effectively with large blocks, has been tried on the terrestrial block collected on 2016. In the following paragraphs, some specific aspects related to the processing of single blocks are described.

2.3.2 EO of terrestrial block 2016 (APP). The EO of this block made up of 134 images collected from ground-based stations (see Subsect. 2.2) has been computed in APP. The highest accuracy level ('Very-high') has been selected. This level corresponds to processing the images at full resolution. All the images could be involved in the EO process at the same time. The BBA has also included the estimation of camera calibration parameters and seven GCPs to be used for fixing the datum.

\subsubsection{Surface reconstruction from terrestrial block 2016}

(APP). After the EO has been computed, all the images of this block have been used as input for dense surface matching in APP. The 'High' accuracy level has been setup, which is based on the use of subsampled images at half the original resolution. As reported in a previous paper (Scaioni et al., 2017), the use of the full resolution images ('Very-high' accuracy level) is usually not encouraged, since the impressive increment of processing time is not balanced by an equivalent improvement of the point cloud quality. The final point cloud, as all others generated in this study, has been automatically assigned colors to points by using RGB information from images.

2.3.4 Surface reconstruction from terrestrial block 2016 (BCC). The use of BCC has been motivated by the large number of images captured on the glacier. Indeed, BCC is able

2 In strict meaning, the term 'Structure-from-Motion' should only refer to the automatic procedure for computing the EO of a sequence (or block) of images by concatenating small groups of images that have been registered using feature- to handle large image blocks with a processing workflow faster than APP. The possibility to automatically split the block into 2D or 3D tiles allows BCC to work with a high-data density during the generation of a dense point cloud. Different tiles (with a very small overlapping area) are independently processed to reduce memory consumption without exceeding the actual RAM available in the workstation adopted for data processing (Alienware Aurora R5 with 1 Intel(R) Core(TM) i76700 Processor (4-Cores) and 32 GB RAM, equipped with graphic card NVIDIA(R) GeForce(R) GTX 970 with 4GB GDDR5). Image EO and camera calibration parameters estimated with the APP project has been imported in BCC and assumed as fixed values. So that processing was supposed to start directly from the dense surface matching. On the other hand, some experiments (also with other data sets) revealed some issues in the exchange of parameters between APP and BCC. Although both software packages use the same camera model for calibration (coefficients for radial symmetric and decentering distortion based on Brown's model - see Luhmann et al., 2016), statistics on corresponding image points matched in BCC with fixed EO/calibration parameters imported from APP resulted in a RMSE (Root Mean Square Error) of image coordinates of about 5 pix. This is not consistent with the same values measured in APP, were corresponding RMSE has been better than 1 pix. After some tests, it has been found that such results mainly depend on slight changes in the implementation of Brown's model. It has been therefore decided: to fix the EO parameters and the estimated focal length from APP, and then to run the extraction of TPs to write a new system of equations where new values for the principal point and distortion coefficients are estimated through a BBA. The new results (which do not significantly modify the location of the reconstruction) provided a RMSE of 0.3 pix. After that, dense image matching stage has been run by dividing the area in 4 tiles, setting a data density of 1 pixel and obtaining a final point cloud of more than 740 million points. An example of such a point density is shown in Figure 3.

2.3.5 EO and surface reconstruction of UAV block 2016 (APP). This block consisted of 291 images that has been oriented using APP. The 'Very-high' accuracy level has been set up. Also in this case, the estimate of camera calibration parameters has been carried out within the same BBA adopted for image orientation. This step has been followed by the dense surface matching (at 'High' accuracy level), which has led to the final point cloud.

2.3.6 Fusion of point clouds from terrestrial and UAV blocks 2016. Since both point clouds obtained from 2016 blocks were georeferenced with respect to the same mapping reference system, they could be directly merged. The resulting point cloud was then subsampled at $20 \mathrm{~cm}$ spatial resolution to obtain a complete 3D model of Forni Glacier terminus.

based-matching (Hartmann et al., 2016). After Westoby et al. (2013), in the Geosciences this term often means the whole automatic process to obtain the image-based 3D reconstruction including dense surface matching as well. 


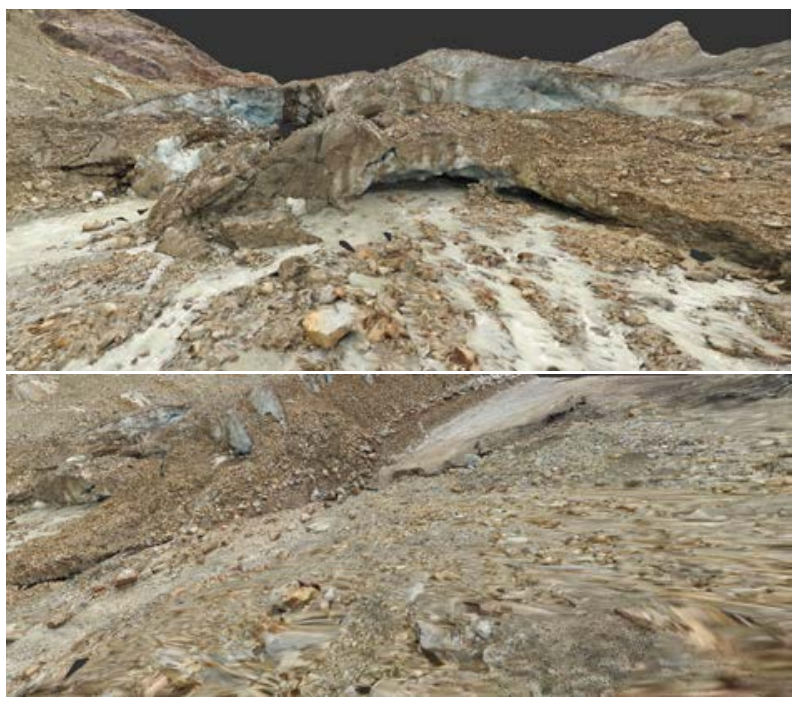

Figure 3. - Two images of the textured point cloud (after meshing) obtained from BCC.

RGB information of points in overlapping areas has been also averaged. The main characteristics of this model is the high resolution on one side, which allows the interpretation of surface features (crevasses, roughness, dip orientation). On the other side, the integration of a point cloud obtained from airborne vertical images to another one from ground-based camera stations, allows to improve the reconstruction of surfaces with different spatial orientation such as those typical of a glacier terminus.

\subsubsection{EO and surface reconstruction of terrestrial block 2017} (APP). This block consisted of 323 images that has been oriented using APP. The 'Very-high' accuracy level has been set up. The entire data set could not be oriented in a single step, but it has been necessary to handle four different sub-blocks ('Chunks') made up of 111 (central part of terminus front), 113 (right side of terminus front), 78 (collapsed area), and 21 (left side of terminus front), respectively. After the independent orientation of each block, they all have been merged by using first the 'Align Chunks' function in APP. In such a case, the alignment has been based on the extraction of corresponding feature points between sub-blocks. The estimate of camera calibration parameters has been carried out within the BBA adopted for the EO of the block including the largest number of images. The set of calibration parameters estimated this way has been fixed in other sub-blocks. In order to accomplish the absolute georeferencing, during data acquisition the coordinates of some camera stations should have been determined using a geodetic GNSS receiver. Unfortunately, due to some technical problems this task failed. The only alternative to overcome this problem has been the measurement of some corresponding points between both data sets of images, but the operation resulted to be very involved due to changes in the image content. Then 47 images from the 2017 depicting some stable areas have been added to the terrestrial block captured on 2016. This new block has been oriented again using
SfM in APP. At this point, five control points have been manually measured on the set of 'shared' images. Since the image coordinates of these points were the same in both blocks, their object coordinates obtained from spatial intersection have been used as GCPs in 2017 block. A RMSE of residuals on GCPs equal to $33 \mathrm{~cm}$ has been found. After merging, the dense surface matching has been applied to reconstruct the point cloud modelling the glacier surface on 2017. The 'High' accuracy level has been set up for processing.

\subsection{Results}

By comparing both point clouds obtained from 2016 (see Par. 2.3.6) and 2017 (see Par. 2.3.7) it has been possible to detect the changes of the terminus of Forni Glacier. In Figure 4 both point clouds are compared. It is out of the scope of this paper to analyze these changes nor to compare the glacier retreat between 2016-2017 to the trend already observed in previous studies, see Fugazza et al. (2017). On the other hand, it is worth here to discuss the effects of a major collapse occurred during September 2017 (see Fig. 1b) and to see how some evident precursory signals of this process can be seen on 2016 point cloud. In a similar way, the forecasting of other similar collapses can be made on the basis of both point clouds.

2.4.1 Properties of point clouds. The point cloud obtained by merging terrestrial and UAV blocks captured in 2016 covers the full terminus of Forni Glacier. In addition, no holes or major occlusions can be noticed. By looking at each 3D geometry, the presence of surface features is easy to detect. It is interesting to highlight the presence of a large collapsed areas (Summer 2016) on the left hydrographic side of the glacier (see Zone A in Fig. 4a). On the other hand, the point cloud derived from terrestrial block surveyed during September 2017 has a smaller spatial coverage. In addition, the lack of nadir images from drones has resulted in several holes in the upper part of the glacier terminus. It should be also remarked that the complexity of the glacier topography was higher in 2017, due to the new collapsed areas and the major fragmentation of the terminus. Anyway, these events are clearly visible in the point cloud, also because the focus of data acquisition was just given to their specific documentation.

2.4.2 Analysis of changes. By looking at both point clouds, a first impressive change concerned the interannual retreat of the glacier front. The average value distance between the medial part of the front was $38 \mathrm{~m}$. The observed shape of the front is quite similar in both years, with the terminus split in two longitudinal sectors by the medial supraglacial moraine. In each sector water may flow out from the glacier, where it is excavating subglacial tunnels (Fig. 3). The thickening of the vault of a portion of the right tunnel was probably the causative reason of the collapse occurred on September 2017 (see Fig. $4 \mathrm{~b}$ ). This resulted in the formation of a big crater (zone B in Fig. 4b), which also had the effect of breaking the ice flow on the last part of the corresponding longitudinal sector, close to the glacier front. The lack of ice feeding will speed up the melting process of this part of the terminus. 
The International Archives of the Photogrammetry, Remote Sensing and Spatial Information Sciences, Volume XLII-3/W4, 2018 Geolnformation For Disaster Management (Gi4DM), 18-21 March 2018, Istanbul, Turkey
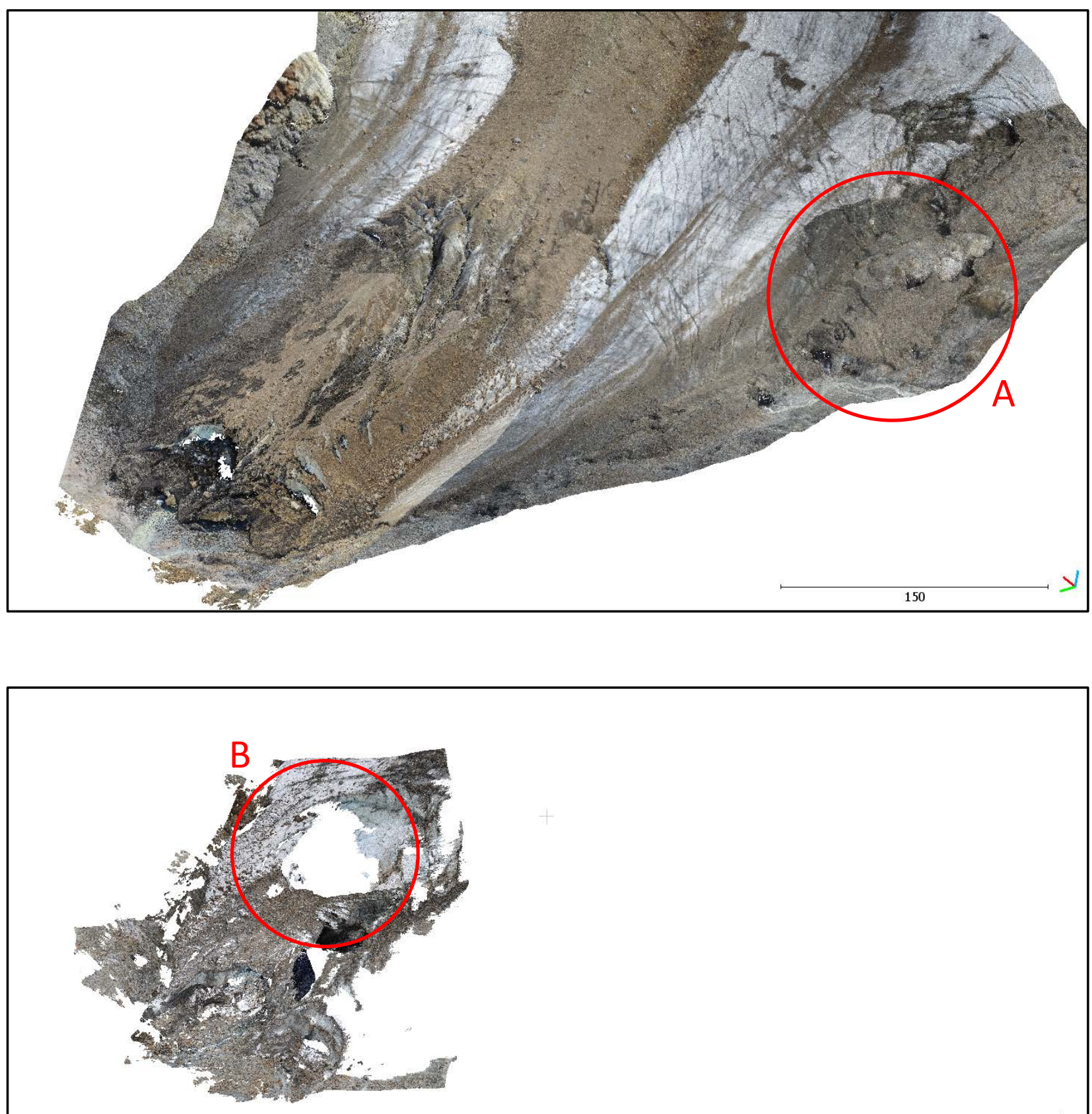

Figure 4. - Point clouds obtained from SfM processing of terrestrial/UAV block captured on 2016 (at the top - 'a') and from terrestrial block captured on 2017 (at the bottom - 'b'). Red circles highlight regions involved in collapsed occurred during 2016 (A) and 2017 (B). Both subfigures are registered in the same reference system, so that corresponding areas can be easily find. 
2.4.3 Risk assessment. During each summer the terminus of Forni Glacier is visited by many hikers and tourists. On one side, tracks to reach some mountain peaks in the nearby go through the terminus. On the other hand, the short walking distance from Branca Hut, which may be also reached using a car service, brings hundreds of tourists every day to the terminus. The easy access allows also non-experts and children to visit this area. Consequently, big collapses like the ones discussed in this paper, and other of minor magnitude, may have serious consequences on people visiting the glacier.

The availability of 3D models obtained from photogrammetric surveys may help understand those areas where collapses are foreseen, and consequently to limit the access to the glacier. In particular, these 3D models may help obtain a three-dimensional view of the problems, and to realize which is the effective region involved. This type of information may then integrate to direct visual inspection, as well as to other investigations (weather conditions, precipitations, ice penetrating radar, hydraulic flow measurements, etc.). Of course, in the future the availability of several 3D models that will be likely captured at least on a yearly basis, is expected to provide a very detailed description of ongoing processes. A better understanding on how they may dynamically evolve since the appearance of precursory signals on the glacier surface and whether there are some parameters that may be related to them, will potentially lead to a more precise forecasting of collapses and then to assess the risk for those people who visit the glacier. To this purpose, the repetition of more data acquisition campaigns during the same summer (e.g., on a monthly-basis), may provide unprecedented information to understand these rapid melting processes, to be generalized to other case studies as well.

\section{CONCLUSIONS AND FUTURE WORK}

While in previous studies the potential of UAV and terrestrial 'Structure-from-Motion' photogrammetry has been evaluated for monitoring changes of Alpine glaciers, the focus of this paper has been given to demonstrate how these types of 3D surveys may help to evaluate the risk of collapses, which may potentially result in casualties among people who visit some glaciers. The paper has specifically dealt with the case study of Forni Glacier, where the risk is quite relevant under current global warming conditions and accelerated melting.

Also in this case, the use of photogrammetry has been demonstrated to be quite supportive, since the analysis and comparison of 3D models allowed to extract useful information to detect potential collapses.

Close-range surveys from drones and ground-based platforms are supposed to be repeated in the future for both long-term (annual basis) and short-term (monthly basis, only during summer), to better depict global and local phenomena contributing to the acceleration of the glacier ablation process. Since a measurement campaign require time, suitable whether conditions, and a team of people, the organization of multiple expeditions is in general a non-trivial task. For this reason, SfM techniques are highly mature to be implemented within Citizen Science initiatives, for instance. People may be trained on how and where images should be collected, while the processing stage may be left to experts. As proposed in Albers et al. (2017), some apps may be also developed to guide users to capture the images following a precise scheme and to obtain redundant data acquisition. As shown in Paragraph 2.3.7, the presence of stable areas may help to register photogrammetric blocks collected at different epochs without the need of GCPs.

\section{Acknowledgements}

This study was funded by DARAS (Presidency of the Council of the Italian Government). The authors acknowledge the Central Scientific Committee of CAI (Italian Alpine Club) and Levissima San Pellegrino S.P.A. for funding the UAV quadcopter. The authors also thank Stelvio Park Authority for the logistic support and for permitting the UAV surveys and IIT Regione Lombardia for the provision of the 2007 DEM. Also the authors would like to acknowledge those colleagues, students and friends who helped with different stages of field operations.

\section{REFERENCES}

\section{References from journals:}

Azzoni, R.S., Fugazza, D., Zennaro, M., Zucali, M., D’Agata, C., Maragno, D., Cernuschi, M., Smiraglia, C., Diolaiuti, G.A. (2017). Recent structural evolution of Forni Glacier tongue (Ortles-Cevedale Group, Central Italian Alps). Journal of Maps, 13(2): 870-878, doi: 10.1080/17445647.2017.1394227.

Carboneau, P.E., Dietrich, J.T., 2016. Cost-effective nonmetric photogrammetry from consumer-grade sUAS: implications for direct georeferencing of structure from motion photogrammetry. Earth Surf. Process. Landforms, 42(3): 473486.

Colomina, I., Molina, P., 2014. Unmanned aerial systems for photogrammetry and remote sensing: A review. ISPRS Journal of Photogrammetry and Remote Sensing, 92: 79-97.

Diolaiuti, G.A., Smiraglia, C., 2010. Changing glaciers in a changing climate: how vanishing geomorphosites have been driving deep changes in mountain landscapes and environments. Géomorphologie: relief, processus, environnement, 2: 131-152.

Eltner, A., Kaiser, A., Castillo, C., Rock, G., Neugirg, F., Abellán, A., 2015. Image-based surface reconstruction in geomorphometry - merits, limits and developments. Earth Surface Dynamics, 4: 359-389.

Fey, C., Wichmann, V., Zangerl, C., 2017.Reconstructing the evolution of a deap seated rockslide (Marzell) and its response to glacial retreat based on historic and remote sensing data. Geomorphology, 298: 72-85.

Fugazza, D., Senese, A., Azzoni, R.S., Smiraglia, C., Cernuschi, C., Severi, D., Diolaiuti, G.A., 2015. Highresolution mapping of glacier surface features. The UAV survey of the Forni Glacier (Stelvio National Park, Italy). Geografia Fisica e Dinamica del Quaternario, 38: 25-33. 
Fugazza, D., Senese, A., Azzoni, R.S., Maugeri, M., Diolaiuti, G.A., 2016. Spatial distribution of surface albedo at the Forni Glacier (Stelvio National Park, Central Italian Alps). Cold Regions Science and Technology, 125: 128-137.

Fugazza, D., Scaioni, M., Corti, M., D’Agata, C., Azzoni, R.S., Cernuschi, C., Smiraglia, C., Diolaiuti, G., 2017. Combination of UAV and terrestrial photogrammetry to assess rapid glacier evolution and conditions of glacier hazards. Natural Hazards Earth System Science Discussion, available at https://doi.org/10.5194/nhess-2017-198 (last access on 20 ${ }^{\text {th }} F e b$ 2018), under review.

Hartmann, W., Havlena, M., Schindler, K., 2016. Recent developments in large-scale tie-point matching. ISPRS Journal of Photogrammetry and Remote Sensing, 115: 47-62.

Kerr, R.A., 2012. Experts Agree Global Warming Is Melting the Word Rapidly. Science, 338, p. 1138.

Luhmann, T., Fraser, C., Maas, H.-G., 2016. Sensor modelling and camera calibration for close-range photogrammetry. ISPRS J Photogramm Remote Sens, 115: 37-46.

O’Connor, J., Smith, M.J. James, M.R., 2017. Cameras and settings for aerial surveys in the geosciences: optimising image data. Progress in Physical Geography, available online at https://doi.org/10.1177/0309133317703092.

Smiraglia, C., Azzoni, R.S., D’Agata, C., Maragno, D., Fugazza, D., Diolaiuti, G.A., 2015. The evolution of the Italian glaciers from the previous data base to the new Italian inventory. preliminary considerations and results. Geografia Fisica e Dinamica del Quaternario, 38: 79-87, doi: 10.4461/GFDQ.2015.38.08.

Westoby, M.J., Brasington, J., Glasser, N.F., Hambrey, M.J., Reynolds, J.M., 2012. "Structure-from-Motion" Photogrammetry: A low-cost, effective tool for geoscience applications. Geomorphology, 179: 300-314.

\section{References from books:}

Scambos, T., Hulbe, C., Fahnestock, 2003. Climate-induced ice shelf disintegration in the Antarctic Peninsula. In: Domack, E.W., Burnett, A., Leventer, A., Conley, P., Kirby, M., Bindschadler, R. (Eds.), Antarctic Peninsula climate variability: a historical and paleoenvironmental perspective. Washington DC, American Geophysical Union (Antarctic Research Series No. 79), pp. 79-92.

\section{References from Other Literature:}

Albers, B., de Lange, N., Xu, S., 2017. Augmented Citizen Science for Environmental Monitoring and Education. Int. Arch. Photogramm. Remote Sens. Spatial Inf. Sci., Vol. XLII, Part 2/W7, pp. 1-4, doi: 10.5194/isprs-archives-XLII-2-W7-12017.

Barazzetti L., Forlani G., Remondino, F., Roncella, R., Scaioni, M., 2011. Experiences and achievements in automated image sequence orientation for close-range photogrammetric projects. In: Proc. Int. Conf. 'Videometrics, Range Imaging, and Applications XI', 23-26 May, Munich (Germany), Proc. of SPIE, Vol. 8085, paper No. 80850F, 13 pp. (e-doc), DOI: 10.1117/12.890116.
Rutzinger, M., Höfle, B., Lindenbergh, R., Oude Elberink, S., Pirotti, F., Sailer, R., Scaioni, M., Stötter, J., Wujanz, D., 2016. Close-Range Sensing Techniques in Alpine Terrain. ISPRS Ann. Photogramm. Remote Sens. Spatial Inf. Sci., Vol. III, Part 6, pp. 15-22, doi: 10.5194/isprs-annals-III-6-15-2016.

Scaioni, M., Corti, M., Diolaiuti, G., Fugazza, D., Cernuschi, M., 2017. Local and General Monitoring of Forni Glacier (Italian Alps) Using Multi-Platform Structure-From-Motion Photogrammetry. Int. Arch. Photogramm. Remote Sens. Spatial Inf. Sci., Vol. XLII-2, Part W7, pp. 1547-1554, doi: 10.5194/isprs-archives-XLII-2-W7-1547-2017.

Wenzel, K., Rothermel, M., Fritsch, D., Haala, N., 2013. Image acquisition and model selection for multi-view stereo. Int. Arch. Photogramm. Remote Sens. Spatial Inf. Sci., Vol. XL, Part 5W, pp. 251-258. 